\title{
Making a Rhombicosidodecahedron: Mathematical Thinking Revisited
}

\author{
ÖZLEM ÇEZIKTÜRK ${ }^{1}$, SINEM INNCE $^{2}$, KÜBRA KARADENIZ $^{3}$, ZÜLAL \\ KENAR $^{4}$, AND GÜLAY YALIM ${ }^{5}$
}

\begin{abstract}
A rhombicosidodecahedron (an Archimedean solid with 30 square, 20 triangles, and 12 pentagon faces) was redeemed from 60 pieces by modular origami. This study used a qualitative research case study as it asked about how participants experienced this construction process of rhombicosidodecahedron. Preservice primary mathematics teachers from a mathematics and art course were participants of the study. Additionally, one student; the first student who came out with the totally symmetric and no damaged object was interviewed for the assembly process. Mathematical thinking throughout the process was noted. Student brought her/his previous experiences as much as specific aptitudes. Student took this project as a creative writing piece so that the process gone through similar phases as intro, progress, and artifact. Deformations and sinking occurred but student investigated the specifics of the real mathematical object did it without a fault. To deal with problems occurred in the phases; students used a creative insight as using paperclips to attach modules and assembly of half spheres. Two main processes; organizational and structural took place in the creative model formation and assembly. Suggestions and future studies are also discussed.
\end{abstract}

\section{Keywords}

Mathematics and art, modular origami, rhombicosidodecahedron

1. *Corresponding author: Department of Mathematic Education, Ataturk Faculty of Education, Marmara University, Istanbul, Turkey; ozlem.cezikturk@marmara.edu.tr

2. Department of Mathematic Education, Marmara University, Istanbul, Turkey; sinemince@marmara.edu.tr

3. Department of Mathematic Education, Marmara University, Istanbul, Turkey; kubrakaradeniz44@gmail.com

4. Department of Mathematic Education, Marmara University, Istanbul, Turkey; Zlal_10@hotmail.com

5. Department of Mathematic Education, Marmara University, Istanbul, Turkey; yalimgulay@gmail.com 


\section{Introduction}

In 2017, Turkish middle school math curriculum, art and aesthetics sensitivity as much as psychomotor abilities and concrete materials are emphasized. Modular origami is a special type of origami in which the folder creates many identical units and then places the units to form a larger shape such as a platonic solid. Here, the folder experiences a three dimensional mode of thinking (spatial reasoning), which is a much higher level of thinking (Wenciker \& Flynn, 2004). Modular origami helps generation of unique solutions and resultantly enhances the mathematical power of the students. Through modular origami, teachers may increase learning through problem solving phenomenon. Two things are enriched: procedural thinking and cooperative learning. Identical pieces fit together so that a final shape is developed in a more spatial and creative way. Wenciker and Flynn (2004) name this stage as "elevated thinking" because students experience mathematics in a very different way, not only specific and simple shapes but also their relationships with each other geometrically are explored. It is a constructivist and student-centered activity for students in all ages. In modular origami mostly, what is challenging is the assembly of individual parts. Meyer and Meyer (1999) list strategies to develop mathematical thinking: procedural thinking, spatial manipulation, mathematical discourse through directions, diagrams, "talking" of mathematics, and hands-on and minds-on instructional practices. Students learn from each other; even though there is a designated teacher. Neatness is important. It helps the final piece to fit together much better and without any unwanted flaws. Students explicitly use geometric terms and discover relationships in the action. The folding process frequently reveals certain symmetries. Studying those helps in understanding symmetry concept in context. Origami can act like an activity; open-ended, inter-connected, reflective of the epistemology of the mathematics that our students can experience. Shimabuku (2010) points to the necessity of defining terms in modular origami for un-informed students. Vertex is the corner of the origami where mostly three modules meet. An edge is either a module folded in half or two or more modules meet to build edges of polygons. Face; is either stellated corners come out, or where polygons are positioned through the connection of two, three, four, five, or six modules making the corners of the polygons.

A polyhedron is a 3-dimensional figure made up of polygons in the faces with straight edges. The word comes from two origins: hedron means "base" or "seat" and poly means "many." August Ferdinand Mobius gave a description of polyhedra in 1865 with two specialties (Krishnan, 2002): (1) the sides of exactly two polygons meet at every edge and (2) it is possible to travel from the interior of one polygon to interior of any other without passing through a vertex. While naming polyhedra -hedron- is the Greek word meaning "base" or "seat" and the preceding word stands for the number of faces that each solid has. From a couple of classifications, Platon named five polyhedra. There are 5 platonic solids: cube (uniform 6 square faces), tetrahedron (uniform 4 equilateral faces), octahedron (uniform 8 equilateral faces), and dodecahedron (12 pentagon faces), and icosahedron (uniform 20 triangle faces) (Krishnan, 2002). Platonic Solids are convex polyhedra with each face congruent while on the other hand, Archimedean solids are convex figures that can be made up of two or more types of regular polygons. A rhombicosidodecahedron is counted as an Archimedean Solid by Kepler. The rhombicosidodecahedron is also known as the 
small rhombicosidodecahedron. It is a uniform polyhedron with 20 triangles, 30 square, and 12 pentagon faces (Eusebeia, 2014). Hence, it has 62 faces altogether (Figure 1). One important feature of a polyhedron is its number of vertexes, edges, and faces. Descartes-Euler Formula stands for $\mathrm{V}+\mathrm{F}-\mathrm{E}=2$ (Pearce, 2010). Here $\mathrm{v}$ stands for number of vertexes, $\mathrm{F}$ is for number of faces and $\mathrm{E}$ is for edges. Most of the polyhedrons suits to this formula though, there are some which does not. If we check whether rhombicosidodecahedron suits to this formula or not, we see that $60+62-120=2$, hence it is applicable.

In the book of Simon, Arnstein, and Gurkewitz (1999), rhombicosidodecahedron is assembled from a module called gyrescope module (Figure 2). It is made of 60 modules. Each module consists of two square positioned on 45-degree rotation of the other. In each square, diagonals and middle creases are made. In the 2nd stage of the module construction, one square is folded into squares of $1 / 4$ th of the first square. And the other square is folded into two triangles of again $1 / 4$ th of the first square. In the 3 rd stage of the module, these two pieces are folded one in the other. In this stage, also down parts are folded inside. In the fourth stage, assembly is so that each module is part of a one 3 -sided ring, one 5-sided ring, and two 4-sided rings. Its vertex description is seen as $(3,4,5,4)$ in some books (Figure 3). Bell (1986) comments on Freudenthal's (1905-1990) "Didactical phenomenology" through stating that the aim is the constitution of the mental objects in relation with the concept and its context. Bell (1986) states that Freudenthal (1905-1990) points to not only the places of objects but also the places of perceivers both in mutual physical and mental relations. Yes, the start is the object but it follows with more abstract properties of the object- plane, direction, perspective, polygons, circles (rings), surfaces of revolution etc. In that fashion, it should be the basis of the curriculum (Bell, 1986). By talking about the object, students become aware of the final output more deeply. Its presence is felt and its transformation into the mental arena follows through (Brookes, 1986). Freudenthal's (1905-1990) mission is building the strong theory behind as Brookes (1986) points out. Here, conception is a two-sided coin from abstract into concrete and from concrete into abstract (Roth \& Thom, 2009). Conception flourishes as unintended but as a result of bodily experiences. There is web of relations between the experience of the object and the conception of the object. We even learn from others' touching and manipulating the objects if we are aware of the fact. Conceptions also activate prior experiences (Roth \& Thom, 2009). In the literature, there are many examples of constructing modular origami pieces however there are not many studies on asking how students experience this process mathematically. In this study, we studied one special student and her experience with the construction of rhombicosidodecahedron from modular origami modules of Simon et al. (1999). In our study, the following questions aroused from semi-constructed interviews on possible mathematical thinking emerging out of the construction of rhombicosidodecahedron from 60 gyrescope origami modules:

(1) How does mathematical thinking emerge in constructing mathematical object with modular origami?

(2) How does previous learning affect the construction of math models with modular origami?

(3) How do the different assembly techniques flourish through construction process?

(4) How is the module formation affected by math thinking? 


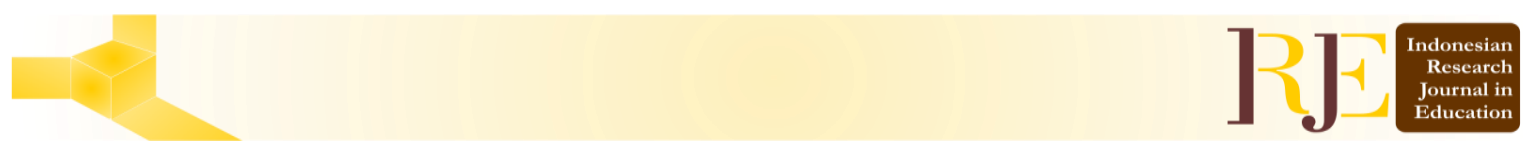

Here from these questions, 2, 3, and 4 came out of the findings. First question was aimed by the study at the beginning. Transcriptions with student gave insight on answers of 2, 3, and 4.

\section{Literature Review}

\section{Origami models of mathematical objects}

Pope (2002) identifies origami as a way to teach problem solving to middle school students. By giving them a math origami object, they can be asked to discover how to make it. Then, they can share their experiences with their peers. This practical experience develops visualization and ability to deal with geometrical properties. They may gain insight as they reflect on the mathematics they had used.

Figure 1. Vertex centered view of a rhombicosdidodecahedron by mathematica software

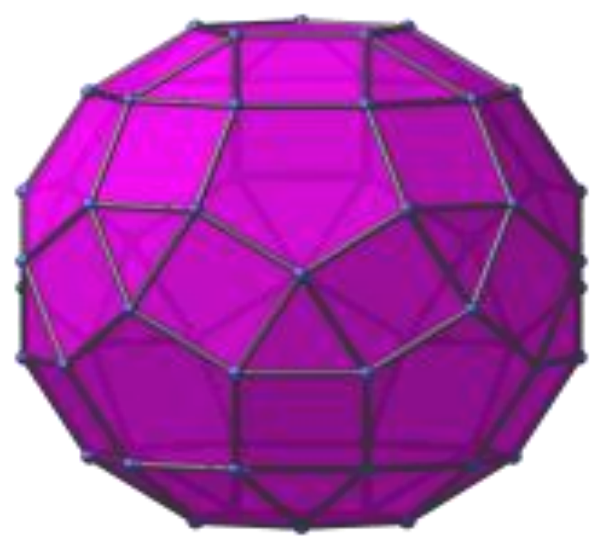

Anc1 and Aslan-Tutak (2015) investigated if origami-based instruction has an effect on spatial visualization, geometry achievement, and geometric reasoning. Their experiment included 184 students divided into control and experiment groups. They gathered data on spatial visualization test of Ekstroum, French, Herman, and Derman (1976). And data on geometry achievement and geometric reasoning came from tests they developed. Results indicated that origami-based instruction significantly affected all. They point to the use of manipulative to foster geometrical understanding (Clements \& Battista, 1992 cited in Ar1c1 \& Aslan-Tutak, 2015). Manipulative achieves this by transitioning from empirical to abstract thinking. This finally enhances geometrical reasoning and spatial visualization. Olkun (2003, cited in Aric1 \& Aslan-Tutak, 2015) argues that spatial ability is mainly on mentally manipulating things and their components. For example, through origami it is supposed that students can visualize certain geometric concepts and relationships by making constructions with paper (Olkun, 2003). And then, these origami pieces can act like manipulative. 


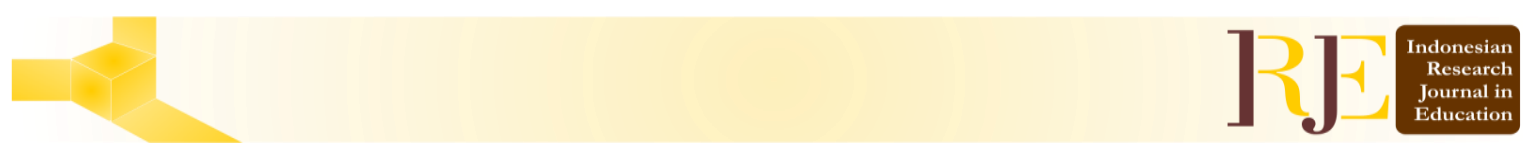

Figure 2. Example rhombicosidodecahedron by Simon, Arnstein \& Gurkewitz.

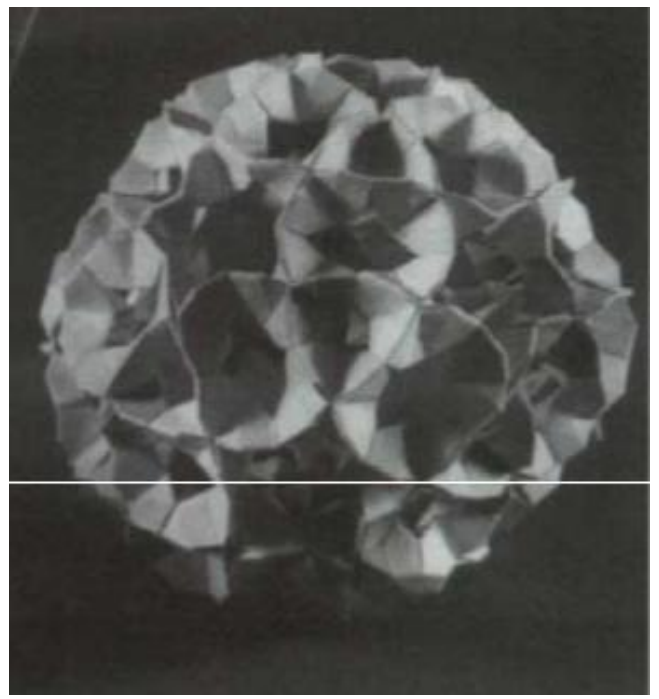

Figure 3. Construction of gyrescope module from Simon, Arnstein \& Gurkewitz. (1999)

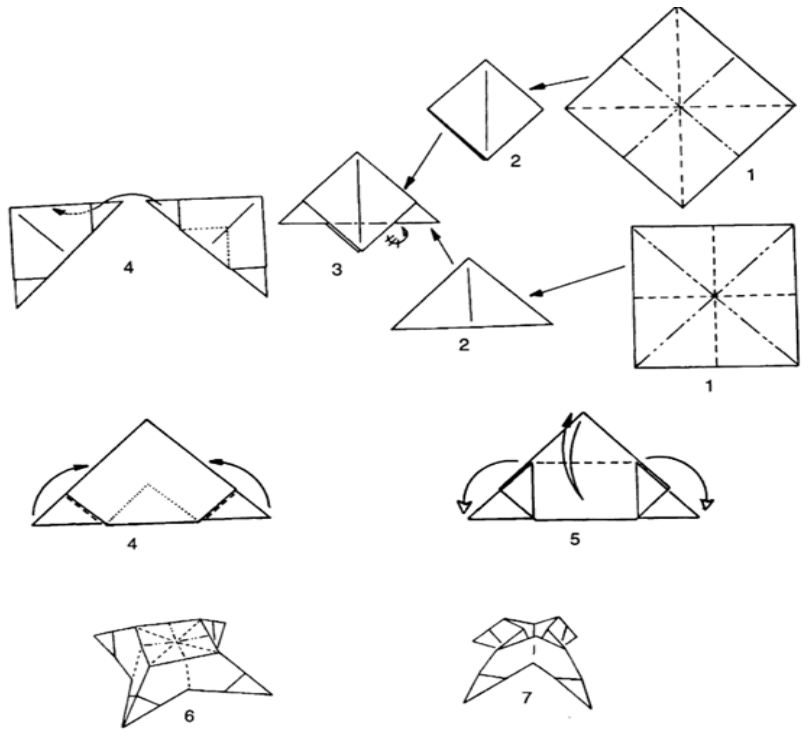

Coloring is a problem stated by Pearce (2010) so that some coloring conditions produce spectacular models. For this two things need to be considered: 1) no two modules of the same color are joined 2) the distribution of colors over the model is symmetric or regular in some sense. These conditions give a rise to the questions in graph theory. A module can be thought of an edge with the help of an ad-joint module. A module also can be a vertex where three modules meet. Çakmak et al. (2013) studied the effect of origami-based instruction on spatial ability. They founded positive significant effect. They also have seen positive opinions of students regarding origami use in the classroom. They 
created geometric shapes and transform paper from 2-D into 3-D. Origami models provide experience in spatial reasoning. Also students' visualization skills could be developed through active exploration with physical models. They have searched for if there is any difference with respect to different grades and they have found no difference with respect to grade. Treatment longed for 10 weeks. It looked for pretty much origami-based instruction inside a classroom other than origami courses. They found that students were given an opportunity to learn the mathematical concepts through paper folding. Flourishing concepts were triangle, square, rectangle, angles, diagonal, pentagon, trapezoid, sides, quadrilateral, symmetry, hexagon, parallelogram, geometrical object, fractions, rhombus, deltoid, area, length, line and rotation. Cognitive skills are used as well. Also, they develop psychomotor skills, improve imagination, creativity, intelligence, make them feel relaxed (Levenson, 1995; Tuğrul \& Kavici, 2002). In the study, there was no control group.

Also, Çakmak (2009) studied 38 4-6 $6^{\text {th }}$ graders in her dissertation to see the effect of origami based instruction on spatial ability (spatial visualization and spatial orientation). Students also gave reflection papers related to origami-based instruction in order to examine their perceptions. The origami pieces were crane, jumping frog, magic star, water bomb, fish and hat, spinner, cube, box, heart and star box. Gür and Kobak-Demir (2017) studied qualitatively, with 18 secondary pre-service math teachers. They used semi-structured interviews and 3-D tangible materials. Robichaux and Rodrigue (2003, cited in Gür \& Kobak-Demir, 2017) identified origami helpful for math problem solving abilities via a case evaluation method. They have carried the study for 14 weeks. By triangulation, the results indicated that origami improves geometry success and geometric reasoning ability. Sze (2005) saw origami as an entry point to mathematical discourse. The idea of perspective becomes an important point of discussion. Teachers can also discuss the viewing angle of the audience. In geometry of paper folding, a straight line becomes a crease or a fold. Folding paper is analogues to mirroring one half of a plane in a crease, thus folding means both drawing a crease and mapping one-half of a plane onto another. This procedure can be named as finding symmetry as well. It also facilitates higher order thinking opposed to belief in general. Higher order thinking is developed by asking beforehand what will be made, asking to visualize in mind, encourage generalizations on the effects of folds, asking and keeping track of symmetries in models while folding. Here neatness, accuracy, and precisions become highly important. These can be achieved by soft fold and sharper crease after being sure. Matsubara and Celani ((2007) gave examples of physicians and engineers for origami as structural applications of it as the fold as a structural edge, which gives rigidity without creating excessive weight. Other kinds of mortises for the same types of modules apply. Here, the difficulties lie exactly in the mortises. Two kinds of symmetry groups as bi-dimensional symmetry groups and 3-D symmetry groups are listed. Former includes frieze patters, wallpaper cyclic and dihedral groups while latter includes crystallographic structures as of kusudama. Budinski (2016) studied faces of the polyhedral, and consequently, polygons of which the polyhedron faces are made. The faces meet along their edges; the edges meet at the vertices which are the point each vertex of the platonic solid has the same number of meeting faces.

Surface area of a tetrahedron $(\sqrt{2}) a^{2}$, of an octahedron $(2 \sqrt{3}) a^{2}$, of an icosahedron $(5 \sqrt{3}) a^{2}$. Here a stands for the edge of the smallest face building unit. Total area finding 
could act like an origami project that could be experienced by whole class. Thinking of the flexibility and compactness of origami structures, this is not a surprising fact. Even in space research some sun energy panels reflect the structure of origami since origami preserves space and valuable material. Resultantly, a new kind of cell phones may include some origami reflecting structures so that they become more flexible at hand and in pockets and they hold a smaller space.

\section{Mathematical thinking}

In the middle school mathematics curriculum, MEB (2013) listed mathematics thinking one of the musts of the curriculum. It is assumed that to think mathematically, in the 2013 and in 2017, 5-8 curriculum, use of mathematical terminology for explaining and sharing mathematical thinking is thought to be ability all students must have (MEB, 2017). Stacey (2006) saw schooling as the main aim and way of mathematics learning. As her perspective, mathematical thinking covers investigation of examples, generalizing, deducing relational facts, and explains reasons systematically (Stacey, 2006). A mathematicians' mathematical thinking is a long process as can be seen and understood from this definition. Modeling and building functional relationships may be a way to experience what mathematician study (Stacey, 2006).

Some other researchers widen the definition of the mathematical thinking as guessing, induction, deduction, descriptions, generalizing, giving examples, reasoning with or without figures, correcting, perception, representational modes, pattern identification (Alkan \& Bukova-Güzel, 2005; Ersoy \& Güner, 2014; Schoenfeld, 1992; Yıldırım, 2015). It may even include, understanding problems, abstract thinking, numerical thinking, mathematical modeling, looking for certainty and pattern, evaluation of arguments, building hypotheses, and testing them (Alkan \& Bukova-Güzel, 2005; Kahramaner \& Kahramaner, 2002; Wares, 2016). Ultimate product may become important. Analysis with graphics, and figures may help understanding the structure and relations within (Schoenfeld, 1992; Yildırım, 2015). Stacey (2006) points to teachers' mathematical thinking education to foster mathematical thinking in students. From many methods to teach mathematical thinking, Tataroğlu-Taşdan et al. (2013) stress discovery learning, problem solving, mathematization and constructive learning. It should be thought as a dynamic process rather than a static one (Henningsen \& Stein, 1997; Tataroğlu-Taşdan, 2013). There may be some faults in processes, underlying meaning may be surpassed and this may cause in hindering mechanical reasoning. Sometimes, the process may not be as systematic as intended. Most importantly, mathematical focus point could be missed. Sometimes, the task or the question may not be suitable for the student. Or the time may be less than needed. Thinking generators of the task should be carefully detected and used. In all these problems, teacher should be a fighter, not the student. Fraivillig, Murphy, and Fuson'un (1999) state that teachers mostly favor mathematical thinking but they act inadequately in flourishing and expanding it. Since, mathematical thinking is a deep concept; case studies are a must in identifying and investigating it. Origami is stated in terms of instructions in Internet so that it is open to more in-depth research studies on mathematical thinking and origami. For every stage in 

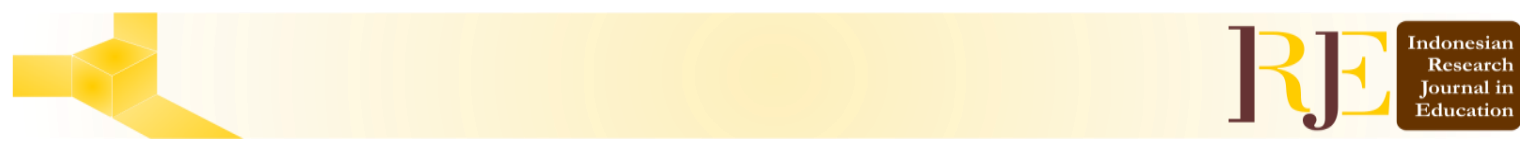

education, it becomes a thinking tool. Mathematical thinking emerges in following stages: preparation of model, in module construction, in assembly, and in artifact.

\section{Methodology}

\section{Rationale}

To deal with the extremities, qualitative research design ideas help. Sooner or later all students came up with a finished product. But some came with symmetry problems; some came with deformations and sinks. Qualitative research points the most and the least. Here, the student who came up with a correct artifact was interviewed under the case study approach. Interviews are good for investigating procedures. Here the construction process was analyzed from student' sayings. This study used a case study approach. A case study deals with specific cases, situations, person's experience with the topic. We used Yin's (2014) and Merriam's (1998) approach to case study. In Yin's approach (2014), an empirical inquiry investigates a contemporary phenomenon (the case) in depth and within its real-world context. In Merriam's (1998) approach, an intensive, holistic description and analysis of a bounded phenomenon such as a program, an institution, a person, a process, or a social unit. Here, a holistic analysis of the experience of a student with building a modular rhombicosidodecahedron origami was aimed. Student was special since she was the first student who came with a correct and flawless model in the given time frame. The modules of the structure were well formed, colors, and the shape of the mathematical object was structurally correct. Case study is a bounded study since there is no chance to generalize the findings but in itself this kind of study gives a full description of the case whether it is a program, or a person or a situation. Interviews help in getting the story behind a participant's experiences. The interviewer can pursue in-depth information around the topic (Mcnamara, 1999).

\section{Data generation and collection}

In the course, students studied foundations of origami, mathematical explorations with origami as of modules from square and rectangle papers, investigated area divisions and how they can be demonstrated via origami and origami theories. They were able to fold platonic solids from sonobe modules. As one final work, they would form rhombicosidodecahedron from 60 sunkated gyrescope modules. Modules consisted two squares put on top of each other by 45 degrees' rotational transformation (figure 3). From the formed octahedron, modules were bounded into each other by 4-3-4-5 rule. The mathematical object formed has 62 faces (20 triangle-30 square and 12 pentagon). Its symmetry group is listed under Ih, H3, [5, 3], (+532), order 120 and listed under Archimedean solids. The name comes from 30 square faces lie in the same plane as of rhombic triacontahedron which is dual to icosidodecahedron. Through partially constructed interview questions, student felt free in answering main questions, then researcher posed follow up or probe questions to detail the information student stated. It is important that the researcher should describe the essential features of the case; nothing more and nothing less 
(Abakpa et al., 2017). We have started with a mathematical object but we did not know we would come up with such innovative assembly techniques as used (using paper clips and half spheres). Information rich cases should be driven. In our case, the student was with highly rich background even though we were unaware of. For quality assurance, trustworthiness in qualitative research is tested through four corners: credibility, transferability, conformity and dependability. Credibility answers if the findings are true and accurate, transferability looks for applicability to other contexts, circumstances, and situations. Conformity is the degree of neutrality and dependability is for the extent the study could be repeated by other researchers with the consistency. Confidentiality was assured via not using names or identifying any other information such as gender. We have showed our curiosity regarding what we might not know, hence the subject felt freely to express himself or herself (Chan, Fung, \& Chien, 2013, cited in Abakpa et al., 2017). Case study assures connections between a mathematical concept, in our case; rhombicosidodecahedron, and the complex world in the form of architectural background etc. In this study, it is researched if a highly complex mathematical object developed by many modules could produce a sparkle to withhold meaningful mathematical agenda in the minds of the students. For this reason, a class of students built and origami model of a rhombicosidodecahedron by 60 sunkated modules of Simon et al. (1999). From this class of students, the first student who mentioned that she got the piece right was interviewed and the conversation was taped. The interview was a semi-structured interview. Hence, the researcher somehow leaded the conversation to detect the answers about the construction process, even though there were some questions to begin with as what did you feel?, what kinds of problems occur?, what could be your suggestions to other origamists?

By this project, we asked undergraduate math teachers to search for the mathematical relationships underlying the module while developing the mathematical object. Their answers were collected for lines of mathematical thinking in their writings as their answers to the origami question. The artifacts they made were photographed from many dimensions. Mixed methods research established the study. Number of students was 62 students. These students never made an origami piece that big by themselves before. Although some students' symmetric insight did not help to the formation of the origami piece, some of them did a marveling job. For this project, we only reported the interview results that we obtained with the best student who made rhombicosidodecahedron in the meantime. As the requirements of the "Mathematics and Origami" course for undergraduate mathematics education majors, students made a rhombicosidodecahedron from 60 sunkated gyrescope modules, named and developed by Simon et al. (1999).

\section{Participants}

Participants' characteristics: participants of the study were from one of the top three public universities in Istanbul. Student profile is in the first \% 1. Some of them took the course mathematics and art. In math and art course, two weeks in 14 weeks are allocated for origami and modular origami students. Students first learn basic folds and very simple module called Sonobe. They learn to make five platonic solids from sonobe modules. Study group was spring semester third year pre-school primary math teachers taking the course 

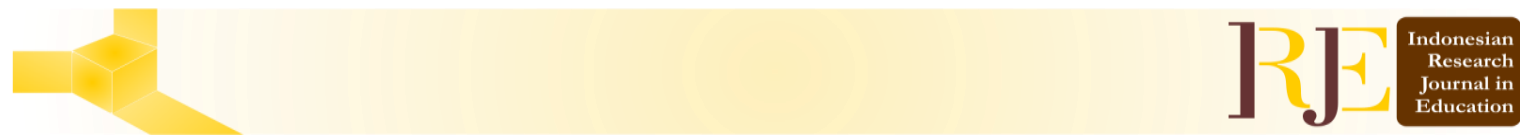

"Math and origami". Data was obtained after students returned back their homework's photos. A rhombicosidodecahedron by modular origami. The module was gyroscope module created by Simon, Arnstein, and Gurkewitz (1999). All students send photos of the models. The first student who sent her model photo as early as possible and correct in symmetry, vision etc. was called for interview.

Interview took place in the office of the instructor. All interview was audio-taped and then transcribed line by line. Partially constructed interview took place. In other words, some questions were pre-decided. Some were follow-ups and probe questions that flourished during the interview. Student was open to share her/ his experience without hesitance. Sayings were neither judged nor criticized. Those were only reported. And she was told so. Some interview questions are; "what kind of problems emerged during the assembly process?", "How can you explain the process of construction?", "What would be your suggestions to your classmates who still work on these?" etc. It is hoped that similar type of research could be carried by other researchers as well. Degree of neutrality (conformity) was ensured by inter-judge reliability. Transcriptions were read by four experts and the themes were decided by them succinctly. This may ensure dependability. In Turkey, recently there are at least three undergraduate courses in different universities as math and origami course. It is possible to create the model rhombicosidodecahedron by required support and help in all levels. Because, the module instructions are fairly easy to follow. Assembly could be a problem but teacher guidance could solve this specific problem.

Figure 4. An example rhombicosidodecabedron made by students

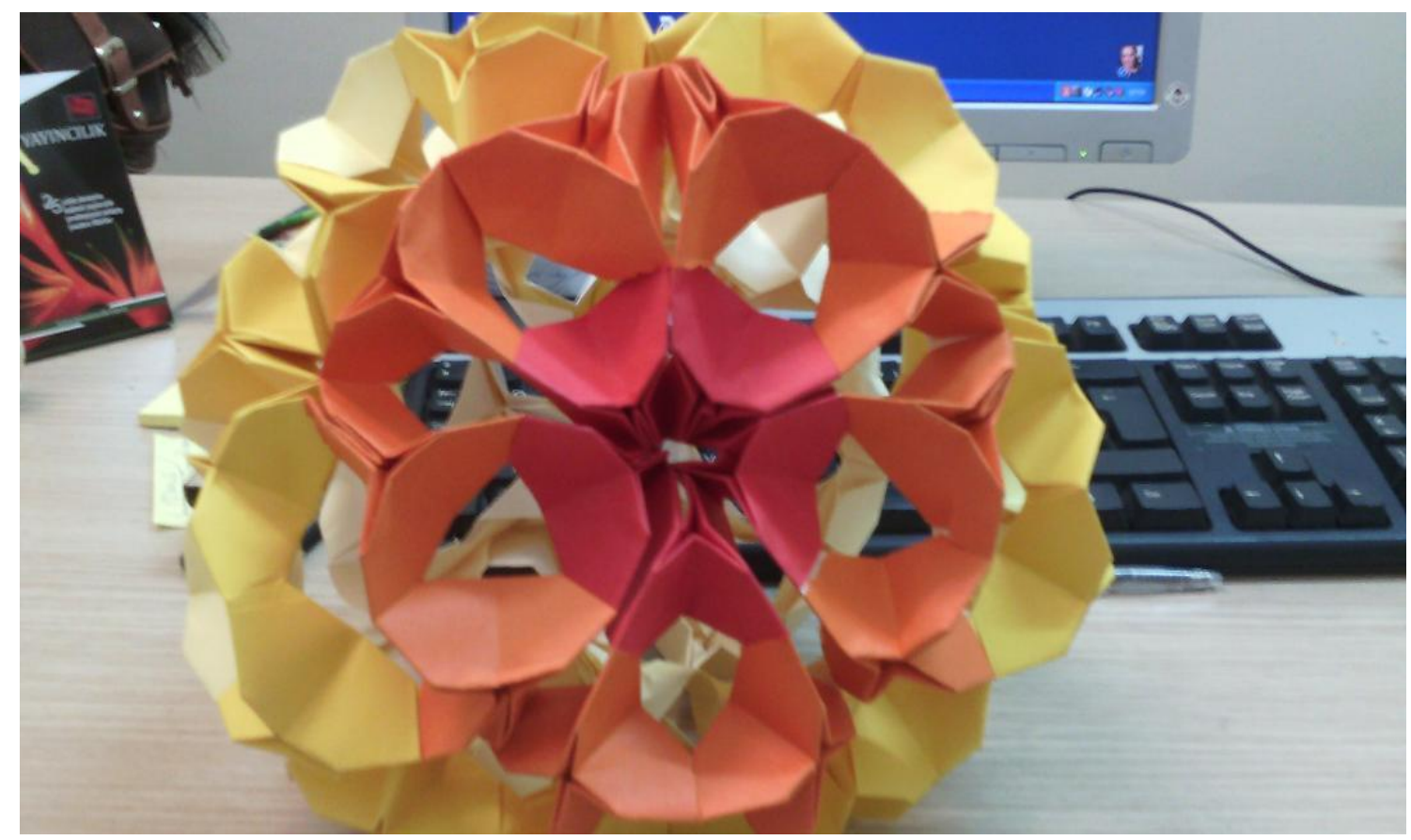



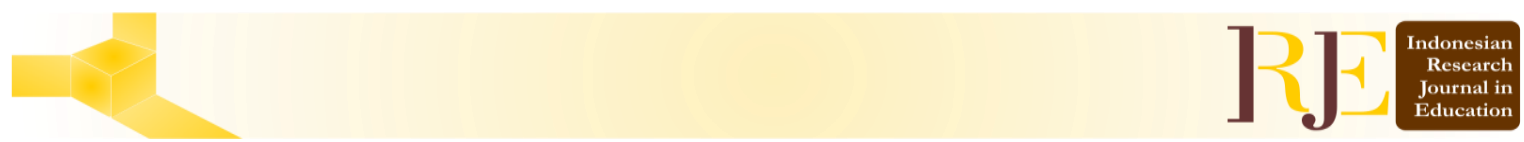

Figure 5. Perspective makes differences on what you see

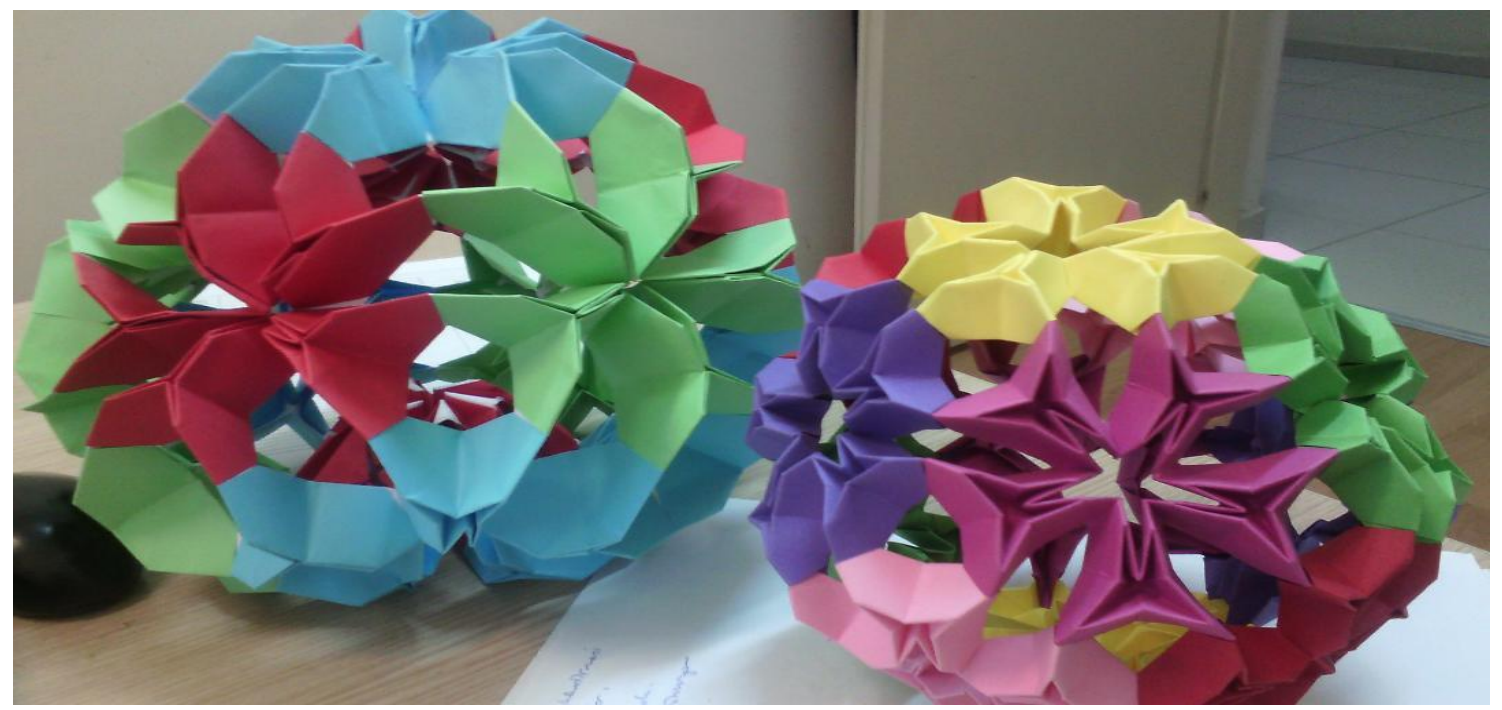

Figure 4 and figure 5 show some different examples of rhombicosidodecahedron constructed by mathematics and origami course students. Here it can be seen that, photos focus on some features and not Show others. For example, figure 4 and figure 5 on the right balls show five rings but figure 5 shows 3 ring instead. The size is related to the size of the module square. All three are different examples. And here all examples were chosen for their representing ability of the rhombicosidodecahedron. Hence, these example balls do not include any sinks, deformations or any symmetry problems. A 3 ring is associated with a triangle face, and 4-ring is associated to a square face and a 5-ring is associated to a pentagon face. In these examples the role of the color may be seen in different photos succinctly (figures $3,4,5,6,7$ ).

Figure 6. Colors may point 5 rings

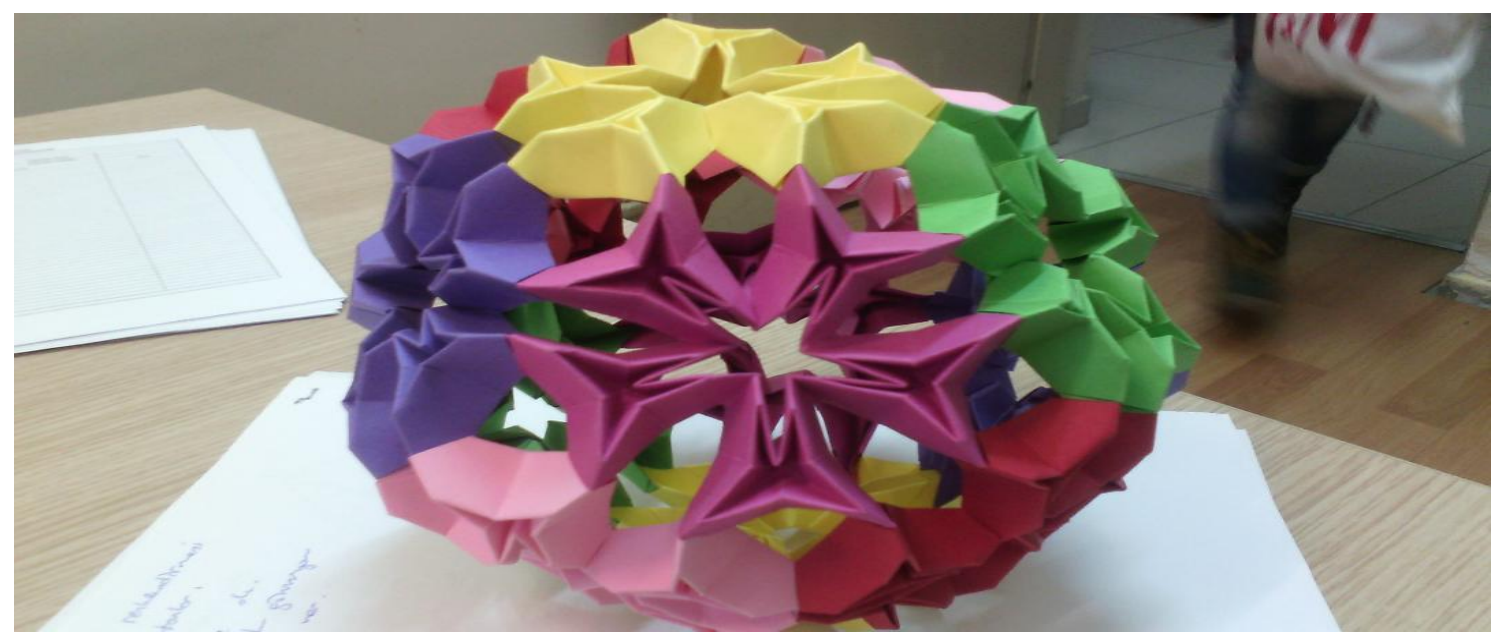



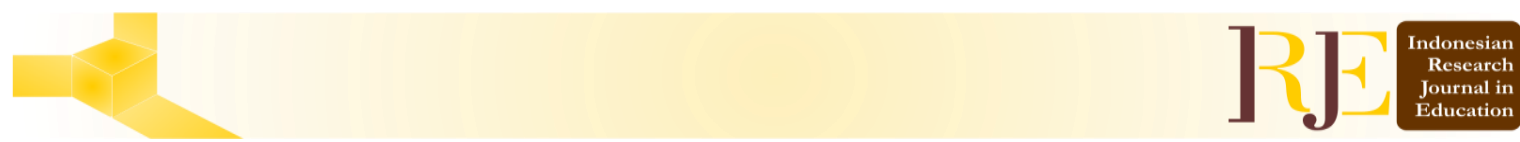

Figure 7. Colors may produce barmony as choices

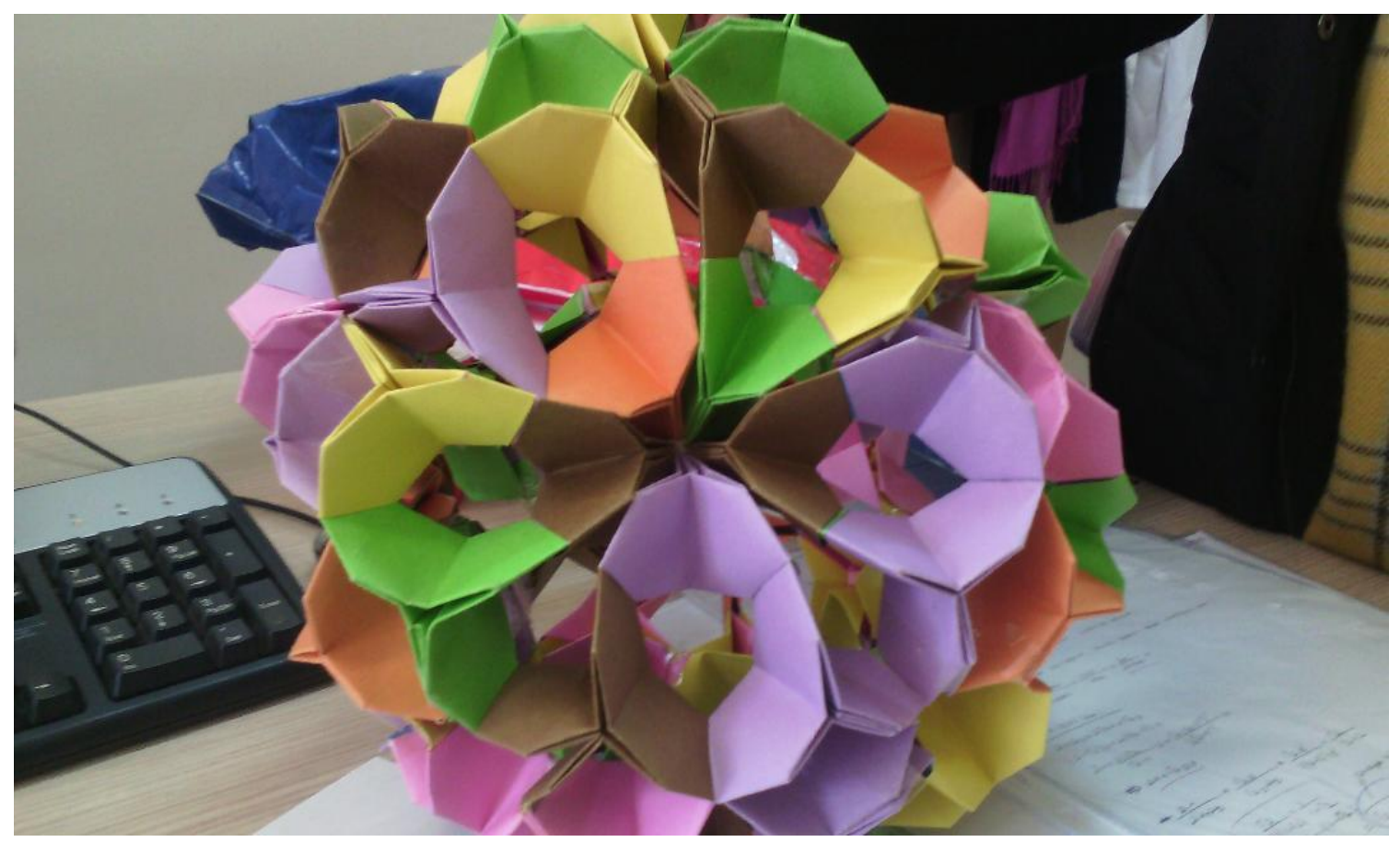

In the following semester, we asked our students to build a hexadecahedron (an egg) by triangular gyrescope module and this time there were two 4 loops in top and bottom and all other loops were either five loop or six loop. We could not talk of the symmetry of this piece in the same way we talked of the rhombicosidodecahedron.

\section{Findings}

\section{Terminology emerging}

It is thought that following emerging terminology is an example of the mathematical thinking formation. Student first used her daily life wordings to explain what was going on in the model. Throughout the study, new terms are needed to be defined: sinking, asymmetry, deformation and ring. Sinking: happened due to either lacking modules in the system or gravity. It was some " $U$ " shaped connections where the system had some problem. Asymmetry: The system; rhombicosidodecahedron is a full symmetric solid i.e. it has a ball shaped structure with 3-4-5-4 module construction structure. Each vertex had either a connection with a 3 ring, or with a four ring or with a five ring. Deformation: It aroused due to repeated use and touch to paper and modules. Paper became either soft as a tissue or leaving some spaces in between while in the assembly process. 


\section{Concepts used in explaining the model}

Then student tried to use the wording she already knows from mathematical background of hers. These words were much more like concepts from mathematics courses that she took. Taped interviews were transcribed. First, mathematical concepts used by interviewee were listed. Some of these concepts were identified as daily life wording: round, emptiness, likeness, form, scale, flat. Some of these concepts were definitely mathematical: corner, triangle, square, $\mathrm{cm}$, proportion, length, number, article, object, perspective, module, 45 degrees, angle, division, constant proportion, calculation, symmetry, multiple, half sphere, point, whole, quadrilateral, pentagon, 1 day, 10 hours, origami, and standard. Here, even though it was hypothesized that more of the daily life mathematical wording would be used and less of the formal mathematical wording. The result conflicted with this guess. This could be due to the fact that the student was a third year mathematics education major and since she was talking to her professor, she felt like using formal mathematics more. But also, this could be explained by student's feeling of more mathematized than she would be in her normal life. Also, instructions of the modular origami, professors' usage of the more formal mathematical concepts could trigger this result. From these listed concepts, most of them are basic geometrical concepts (e. g., square, quadrilateral, angle, point, etc.), some of them were basic arithmetic (division, multiple, calculation, etc.), some were on algebraic relationships (proportion, half sphere, whole, number, etc.) and finally some were measurement concepts (length, hour, 45 degrees, etc.). Hence, by constructing a rhombicosidodecahedron, students' mathematical concept formation and usage was uplifted.

\section{Emerging themes from construction process}

Here, the student tried to explain the assembly process of the model from the particular modules. As she was having some confusion on how to explain the construction process, she tried to make use of her special background on architecture. From transcriptions, emerging themes were identified. Following themes were found to be hidden:

1) Building a round object

S: "Since we build a round object from left to right, from all faces..."

S: "While doing artifact, I have found that it was not hard to build a round object going from a small unit to bigger unit"

2) Bringing out all modules

S: "while gluing small units' unsuitableness occurs."

S: "we decided all colors, measures of squares by ourselves. You set us free."

3) Sinking

S: "Since it is done by paper some sinking happens unwillingly"

S: "From the first point till I bring it to you, certainly some damages will flourish" 
S: "Some sinking occurs resultantly; modules should be that small"

4) Aptitude

S: "At the beginning, I did not think I have the aptitude of handy-crafts"

5) Experience (architecture)

S: "I attend to architecture in university for 1.5 year. It might have helped me in doing this"

6) Mathematical rules (perspective, similarity, proportion, symmetry, mathematical object etc.)

S: "It was supposed to be a totally symmetric object."

$\mathrm{S}$ : "One raw is from square rings, one from pentagon and one from triangle rings"

7) Module integration techniques (paper clip, gluing, two half spheres etc.)

S: "I built my squares first, from there, I made my figures. When you both glue and make, there happens a chaos in ones' brain. Hence, you must do it in order."

S: "With belp of my friend, I made two half-spheres separately and then I brought them together."

8) Paper corrosion

S: "While you are making a whole, unwillingly you may make errors. Thinking if they were due to my mistakes or if they were due to gluing, took some time".

9) Artifact

S: "If more receding object would come out, I would not use two half spheres"

These themes were decided by a group of four researchers. After themes, it is decided if these themes fall into some categories as personal readiness, deformation, construction or mathematics and product.

\section{Mathematical thinking within the process}

Then, we tried to analyze the mathematical thinking process from the construction process, we agreed upon the following structure. 
Table 1. The construction process in- tact

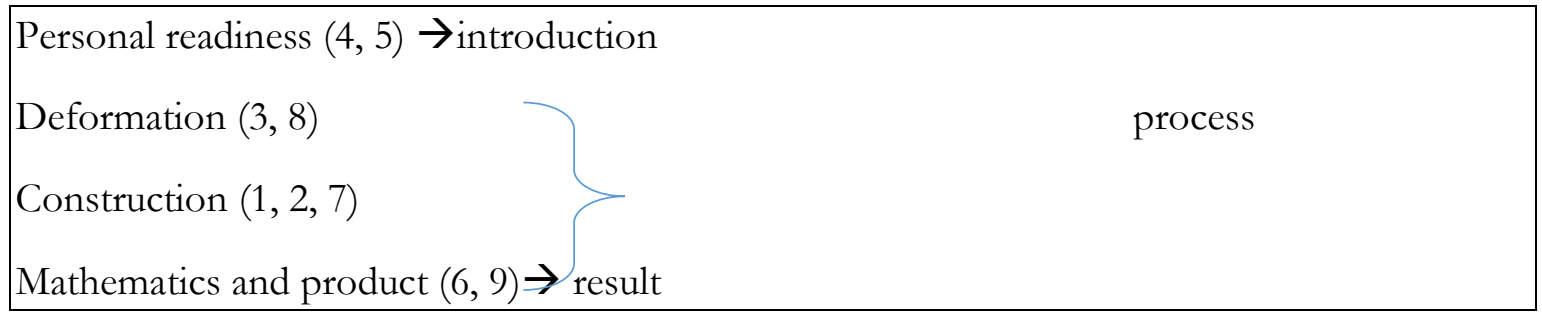

Personal readiness was where student mentioned about her architecture educational experience. She/he was architecture major in another university. She/he was educated there for one and a half year. Then she/he said that she thought this major was not for her/him since it was asking for a lot of dreamy mind while she/he was much more a realist. But she/he said that her/his education as an architect could be a reason why she/he was the first to establish the rhombicosidodecahedron from the class of 60 students. It might have affected her/his creativity and her/his interest in such a kind of constructions. The researcher did not know her/his special status before contacting and interviewing her/him. Even tough, one should be really careful about generalizing the facts coming out of qualitative research; we can infer some general results. We can say that previous learning affects and shapes the construction process since the student tries to build mental structure first by these previous learning sources (Table 1).

Deformation and construction phases acted like a process part of the themes. We may call this stage as process underlying process. There were some problems of the construction as she faced while construction and assembly. For example, some collapses occurred due to gravity and paper's deformation. Same problem occurred in many students as can be seen from some example photos. It may be due to three main reasons: constructors' fault or paper's fault or as a problem occurring by the time passes. This object was totally symmetrical mathematical object hence; the correct piece would be without any collapses. However, many students brought examples with two of three collapses of the object. One was mostly due to construction without obeying the rules given by the Simon et al. (1999) book. Some were not aware of the properties of the mathematical object to begin with. Some did the construction by trial and error, hence the paper lost its formation and some deformations occurred unwantedly. In some, problem was time since thin papers like hand craft papers were not suitable for a construction experience and at least an A4 paper or a cardboard paper was a necessity. Some asked for peer help, and this turned into construct and rebuild phases one following each other. And this resultantly affected the wholeness of the object since it could be a reason of losing the way while working on little problems like those. 3-4-5-4 was a mathematical rule given by Simon et al. (1999) paper. This was in parallel to the mathematical relationships of the rhombicosidodecahedron since it asked for two squares, one triangle and one pentagon in a ring of the module attached (Table 1).

As the final phase, the product (table 1) came out to think about. Student thought mathematics of the object via the wholeness of the object together. Hence, similarity, perspective, proportion brought the object as a correct whole. She/he certainly was aware of the physical properties of the mathematical object as 20 triangles, 30 square, and 12 
pentagon faces. In the vertex view (figure 1) one can see each vertex having corner of one triangle, two squares and one pentagon. In figure 6 it can be seen the vertex view of the rhombicosidodecahedron where triangle occurs as the petals of the flower in the middle and pentagon occurs at the middle and rectangles are hidden in left and right of the triangle due to paper construction. Researchers named these themes as intro, progress and result since they thought that this worked for students as a creative writing piece. In the introduction, their readiness was highlighted by their experience with such origami and constructions, and their aptitude. In the progress phase, they have solved the problem of construction by paperclips, gluing and half spheres. Student said that paper clips were highly helpful but problematic after the artifact since it could be a mess while clearing out those. Half sphere, researchers thought as the most creative since it is not easy to do but object's symmetrical value certainly helped it through. In case of modular origami most of the time, it is advised to add modules one at a time rather than three or more together. This is due to the fact that assembly of bigger modules done by little modules is hard to establish.

Figure 8. The concepts stressed in the creative process

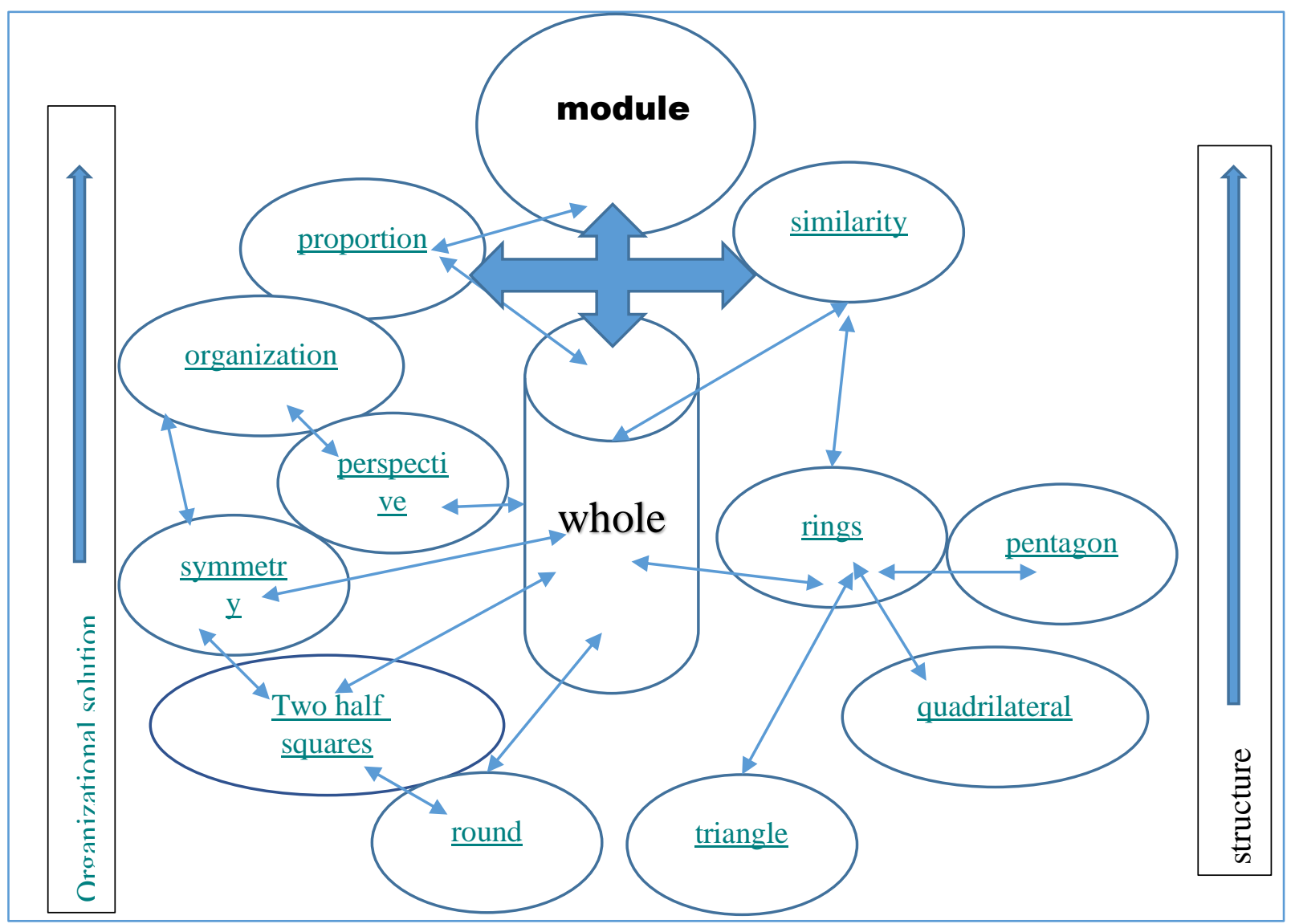




\section{Discussion}

In figure 8, a concept map of the concepts focused on the explanation of the experience could be seen. The whole represents the rhombicosidodecahedron while module represents the unit of construction. Left hand side of the map was in line with the organizational solution of the problem of construction. Right hand side of the concept map was in line with the underlying structure of the rhombicosidodecahedron. Similarity as much as proportion acts on the module to build the whole or in other words; rhombicosidodecahedron. Similarity also acts on the organizational solution process as a piece placement tool. As can be seen from the concept map, each concept helps in building the mental model of the whole as Freudenthal (1905-1990) suggests. Total experience is based on the simultaneous processes of organizational and structural development of the whole mental model and vice versa real mathematical model. Results of the study are parallel with the positive effects of the studies of origami instruction both as an aid and both as by itself (Çakmak, 2009; Çakmak et al., 2013; Gür \& Kabak-Demir, 2017). Even tough, both formal and in-formal concepts are used by student's thinking; there is evidence that their formal relations are favored by the processes of modular construction (figure 8). This is in the line of the mathematical thinking studies in the literature (Alkan \& Bukova-Guzel, 2005; Kahramaner \& Kahramaner, 2002; Tataroglu-Tastan et al., 2013). It is also beneficial to look into the definition of the mathematical model to decide upon the formal mathematical concepts and their required relationships. Mathematical thinking is itself a creative process if it happens naturally. Each piece is sticked into the previous pieces as concept development one on top of the former ones, creation becomes a process situated in other structural processes (Ersoy \& Güner, 2014; Meyer \& Meyer, 1999; Wares, 2016). Using origami in instruction helps in student achievement as this study shows with even one student; hence it is required to imagine what kind of difference it makes to a class of students (Aric1 \& Aslan-Tutak, 2015; Çakmak et al., 2013; Meyer \& Meyer, 1999; Pope, 2002; Sze, 2005). Last but not least, origami polyhedra construction with students helps in advanced mathematical thinking to develop through emerging mental models of 3-D, 4-D mathematical advanced concepts giving birth to many other concepts and processes in between.

\section{Suggestions}

The study might be done again but this time the artifacts could be videotaped from different angles and if possible in 360-degree view. This may show possible deformations, collapses, and symmetrical flows more easily and without hesitation. A group of students could be selected as 3 from top points, 3 from most flowed ones, and 3 from intermediate students. This could give more information on all different types of students in the process. Students could be asked to build the resultant object in certain colors and certain coloring techniques. Then, they could see how coloring takes the specific role and how mathematical problems arise from coloring. Students could be given a questionnaire regarding the process of construction and mathematization. Studies on RME (realistic mathematics education) and mathematical mode origami could be fruitful. Since, it suits to the perpendicular mathematization of RME. Although, students in the following term were given an egg like shape (hexadecahedron) to construct from origami modules (triangle gyroscope module), 
this series of research could be carried with many different mathematical objects. Origamics (data not given in this study) should not be left aside since; its mathematical investigations part is so valuable.

Origami may ease visualization 3-D, 4-D visualization of mathematical solids could set project ideas for students at all ages. From simple cubes to egg shaped, torus shaped or rhombicosidodecahedron shaped solids could act as spatial visualization aid. Students can be asked of which concepts/terms they use in explaining/defining/identifying mathematical solids. Interconnectedness between different mathematical concepts, geometrical rules can be investigated from hands- on models. Complex models can be used to trigger mathematical thinking. Induction from first model to nth one and assembly of them; deduction from mathematical relations one can deduct from visual model, guessing of pattern in assembly, generalization and specialization in discovering modules for same models and using same modules to construct different mathematical solid models etc.

\section{Direction of the study}

Study may act as a starter of these kinds of process studies with math model building origami projects. Use of origami can take a new role as trigger of mathematical thinking. Origami models may promote part to whole relationships, spatial reasoning (in the form of rounding the object), similarities, proportional thinking, geometrical relationships of simple shapes, mathematization, etc.

\section{References}

Alkan, H., \& Bukova-Güzel, E. (2005). Öğretmen adaylarında matematiksel düşünmenin gelişimi [Development of mathematical thinking in pre-service mathematics teachers].Gąi Eğitim Fakültesi Dergisi, 25(3), 221-236.

Abakpa, B., Agbo-Egwu, A.O., \& Abah, J. (2017). Emphasizing phenomenology as a research paradigm for interpreting growth and development in mathematics education, Abacus, The Mathematical Association of Nigeria. Mathematics Education Series, 42(1), 391-405.

Arıc1, S., \& Aslan-Tutak, F. (2015). The effect of origami-based instruction on spatial visualization, geometry achievement, and geometric reasoning, International Journal of Science and Mathematics Education, 13, 179-200.

Bell, A. (1986). Two comments on "didactical phenomenology." For the Learning of Mathematics, 6, 1, 24-26.

Brookes, W.M. (1986). Two comments on "didactical phenomenology." For the Learning of Mathematics, 6, 1, 24-26.

Budinski, N. (2016). Origami as a tool for exploring properties of platonic solids. Bridges Finland Conference Proceedings, 649-654. 
Çakmak, S. (2009). An investigation of the effect of origami-based instruction on elementary students' spatial ability in mathematics, unpublished thesis submitted to M.E.T.U: Turkey

Çakmak, S., Işıksal, M., \& Koç, Y. (2013). Investigating effect of origami-based instruction on elementray students' skills and perceptions. The Journal of Educational Research, 107(1), 59-68.

Ersoy, E., \& Güner, P. (2014). Matematik öğretimi ve matematiksel düşünce [Mathematics teaching and mathematical thinking]. Eğitim ve Ögretim Arastırmalar Dergisi, 3(2), 102-112.

Eusebeia. (2014). The rhombicosidodecahedron, Retrieved from http://eusebeia.dyndns.org/4d/rhombico

Fraivillig, J. L., Murphy, L.A., \& Fuson, K.C. (1999). Advancing children's mathematical thinking in everyday mathematics classrooms. Journal for Research in Mathematics Education, 30(2), 148-170.

Gür, H., \& Kabak-Demir, M. (2017). Geometry teaching via origami: The views of secondary mathematics teacher trainees. Journal of education and Practice, 8(15), 65-71.

Henningsen, M., \& Stein, M. K. (1997). Mathematical tasks and student cognition: Classroom based factors that support and inhibit high-level mathematical thinking and reasoning. Journal for Research in Mathematics Education, 28(5), 524-549.

Kahramaner, Y., \& Kahramaner, R. (2002). Üniversite eğitiminde matematik düşüncenin önemi [Importance of mathematical thinking in the university education]. Istanbul Ticaret Üniversitesi Fen Bilimleri Dergisi, 12, 15-24.

Krishnan, K. (2002). Polyhedra-undergraduate research opportunity program in science. National University of Singapore.

Matsubara, J., \& Celani, G. (2007). Origami's symmetry and applications in architecture. Retrieved from http://www.fec.unicamp.br/ lapac/papers/matsubara-celani-2007.pdf

MacGillivray, L. R., \& Atwood, J.L. (1999). Structural classification and general principles for the design of spherical molecular hosts, Angew Chem Int. Ed, 1018-1033.

Merriam, S. B. (1998). Qualitative research and case study applications in education. San Francisco, CA: Jossey-Bass.

MEB. (2013). Ortaokul matematik dersi okul program, [National curriculum for middle school mathematics] Talim ve Terbiye Kurulu Başkanlığı. Retrieved from http://ttkb.meb.gov.tr/.

MEB. (2018). İlkögretim Matematik dersi Ögretim Programı 1- 8, [National Curriculum for Mathematics 1-8], Retrieved from http://mufredat.meb.gov.tr/ProgramDetay.aspx?PID=329. 
Lengvarszky, Z. (2006). Compound platonic polyhedra in origami. Mathematics magazine, 79(3),190-198.

Matsubara, J., \& Celani, G. (2007). Origami; Symmetry and applications in architecture. Retrieved from http://www.fec.unicamp.br/ lapac/papers/matsubara-celani-2007.pdf

McNamara, C. (1999). General Guidelines for Conducting Interviews. Retrieved from http://www.mapnp.org/library/evaluatn/interview

Meyer, D., \& Meyer, J. (1999). Teaching mathematical thinking through origami. Bridges Proceedings, 191-205.

Pearce, G. (2010). Transitive decomposition of graphs and their links with Geometry and Origami. American Mathematical Monthly, 117(4),303-310.

Pope, S. (2002). The use of origami in the teaching of geometry. Proceedings of the British Society for Research into learning mathematics, 22(3), 67-73.

Roth, W-M., \& Thom, J. S. (2009). Bodily experience and mathematical conceptions: From classical views to a phenomenon reconceptualization. Educational studies in Mathematics, 186-189.

Schoenfeld, A. H. (1992). Learning to think mathematically: Problem solving, metacognition, and sense making in mathematics. D. Grouws, (Ed.), Handbook for research on mathematics teaching and learning (334-370). NewYork: McMillan.

Shimabuku, A. (2010). Paper folding and polyhedron, Retrieved from http://math.sfsu.edu/cm2/papers/ashleyOrigami.pdf

Simon, L., Arnstein, B., \& Gurkewitz, R. (1999). Modular Origami Polyhedra: Revised and enlarged edition. Dover Publications, INC: NewYork

Stacey, K. (2006). What is mathematical thinking and why is it important? Retrieved from https://www.researchgate.net/publication/254408829

Sze, S. (2005). Math and mind mapping: Origami construction. ERIC Digest ED490352. Retrieved from https://files.eric.ed.gov/fulltext/ED490352.pdf

Tataroğlu-Taşdan, B. Çelik, A., \& Erduran, A. (2013). Matematik öğretmen adaylarının matematiksel düşünme ve öğrencilerin matematiksel düşünmelerinin geliştirilmesi hakkındaki görüşlerinin incelenmesi. Kastamonu Ë̆itim Dergisi, 21(4), 1487-1504.

Wares, A. (2016). Origami boxes as a context for rich mathematical thinking. STEM Teaching \& Learning Conference, Paper 1. Retrieved from http://digitalcommons.georgiasouthern.edu/stem/2016/2016/1

Wenciker, B., \& Flynn, P. (2004). Modular origami in the mathematics classroom. Bridges Conference Proceedings, 293- 296. 


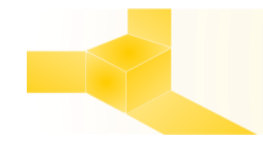

Yıldırım, C. (2015). Matematiksel Düsünme. İstanbul: Remzi Kitabevi.

Yin, R. (2014). Case study research: Design and methods. Los Angeles, CA: Sage.

\section{Biographical notes}

Dr. ÖZLEM ÇEZIKTÜRK is assistant professor at Department of Mathematic Education, Ataturk Faculty of Education, Marmara University, Istanbul, Turkey. Interested in origami, mathematical thinking and reasoning, technology use, Islamic geometrical pattern construction, Dynamic geometry, mathlets, mathematics and art. Email: ozlem.cezikturk@marmara.edu.tr

SINEM INCE has a Master's degree in mathematics education from the Department of Mathematic Education, Ataturk Faculty of Education, Marmara University, Istanbul, Turkey. Email: sinemince@,marmara.edu.tr

KÜBRA KARADENIZ has a Master's degree in mathematics education from the Department of Mathematic Education, Ataturk Faculty of Education, Marmara University, Istanbul, Turkey. Email: kubrakaradeniz44@gmail.com

ZÜLAL KENAR has a Master's degree in mathematics education from the Department of Mathematic Education, Ataturk Faculty of Education, Marmara University, Istanbul, Turkey. Email: Zlal_10@hotmail.com

GÜLAY YALIM has a Master's degree in mathematics education from the Department of Mathematic Education, Ataturk Faculty of Education, Marmara University, Istanbul, Turkey. Email: yalimgulay@gmail.com 